\title{
Acromegaly: current therapies benefits and burdens
}

Acromegaly, caused by growth hormone overproduction, is associated with comorbidities causing significant clinical dysfunction and high mortality risk. Outcomes are hampered by late diagnosis and poor treatment tolerance and adherence. The goal of this paper is to present a scoping review of the benefits and characterize potential burdens of current treatments that may limit achieving disease control or treatment continuity.

Current treatments include transsphenoidal surgery, often followed by the use of synthetic somatostatin analogues or growth hormone receptor antagonists. Radiotherapy is considered an adjunct to treatment for nonresponsive patients or recurrent tumors. Despite therapeutic benefits the burdens to the patient equate to an estimated one quarter of patients discontinuing treatment or that are lost to follow up with up to $88 \%$ of these cases having uncontrolled disease.

Although disease outcomes are improved with early disease identification and prompt treatment, attention to long term treatment adherence is critical to outcomes. The most cost effective and efficacious strategies involve a significant understanding of the individual patient's disease and treatment burdens, the patient's knowledge regarding their disease and the full utilization of all health care team resources. Provider awareness of factors impacting follow-up, the application of precision medicine and implementation of a team approach that actively involves the patients, nurses, and physicians in treatment decisions, location convenient disease monitoring with coordination of treatment for co-morbidities and home drug administration are key factors in facilitating long term treatment adherence.

\section{Keywords: acromegaly, treatment, benefits, burden, adherence}

\section{Compliance with ethical standards}

The authors have no conflicts of interest to declare. Funding for editorial assistance was provided by Chiasma, Inc., Waltham, MA.

\section{Introduction}

\section{- Prevalence}

Acromegaly is caused by the overproduction of growth hormone $(\mathrm{GH})$, most often the result of a pituitary tumor, or adenoma [1]. The estimated disease prevalence is 40 to 125 per million with an incidence of 3 to 4 per million annually [2], generally affecting men and women in equal numbers [3]; however, 17$21 \%$ of patients have been reported to be lost to treatment follow-up where access to health care is universal with up to $88 \%$ of these having uncontrolled disease $[4,5]$.

\section{- Pathophysiology}

Excess GH stimulates insulin-like growth factor-1 (IGF-I) production, particularly in the liver. Together, excess GH and IGF-1 are largely responsible for the clinical characteristics and morbidity of the disease [6]. High levels of IGF1 increase chondrocyte and osteocyte activity causing an overgrowth of bone and cartilage leading to acral enlargement, particularly of the hands and feet, characteristic coarsening of facial features, joint laxity and remodeling associated with progressive joint pain and arthritis symptoms.

\section{- Clinical presentation}

Skin changes, puffiness and edema are most prominent in the face, hands and feet. Oily skin with large pores, hypertrichosis, excessive sweating, hyperpigmentation, skin tags and psoriasis may also occur $[7,8]$. Soft tissue growth and bony changes promote the development of colon polyps, carpel tunnel syndrome, chest wall expansion and airway obstruction, often manifesting as shortness of
Chris Yedinak ${ }^{{ }^{1}}$, Karen J. Pulaski-Liebert ${ }^{2}$, Daphne T. Adelman ${ }^{3}$ \& Jessica Williams ${ }^{1}$

${ }^{1}$ Northwest Pituitary Center, Oregon Health \& Science University, Portland, OR

${ }^{2}$ Neuroendocrine and Pituitary Tumor Clinical Center, Massachusetts General Hospital, Boston, MA

${ }^{3}$ Division of Endocrinology, Metabolism and Molecular Medicine, Northwestern University, Evanston, IL

*Author for correspondence: yedinakc@ohsu.edu 
breath, sleep apnea and poor oxygenation [8]. Hypogonadism may lead to infertility $[9,10]$. IGF-1 also regulates myocytes, carbohydrate metabolism and insulin sensitivity manifesting in a range of comorbidities such as heart disease, hypertension and diabetes [6,11,12]. Disease treatment therefore is multidimensional.

A negative psychological status has been reported among patients with acromegaly which is comparable to patients with other chronic diseases [13]; however, body image issues are considerably greater for patients with acromegaly $[14,15]$.

\section{- Diagnosis}

Similar to other rare diseases, the road to the diagnosis and management of acromegaly by a specialist or referral to a pituitary center is often circuitous. The onset of symptoms may be slow and insidious and diagnosis often does not occur for up to 10 years $[9,10]$. If untreated, disease co-morbidities contribute to significantly enhanced mortality which is 2-4 times higher than the general population [16-19] but lifespan with controlled GH is associated with normal lifespan [20]. It is not uncommon for patients to present to multiple healthcare providers, including endocrinologists, many of whom may lack experience with this rare disease, thus contributing to a delay in diagnosis [21]. This frequently occurs after a preliminary diagnosis of a pituitary tumor during evaluation of visual changes or headaches and not based on the recognition of systemic signs and symptoms $[22,23]$. Delay in diagnosis also risks the compounding of physical deterioration secondary to the progression of co-morbidities and may serve to decrease the patient's confidence in health care providers. It is not uncommon now for patients to refer themselves for evaluation based on readily available information obtained from the internet $[10,22]$. These long, physically and emotionally costly delays in diagnosis are often followed by burdensome, albeit efficacious treatment that may not totally ameliorate symptoms or restore quality of life.

\section{Current treatment of acromegaly}

No current treatment has demonstrated complete efficacy. All are associated with risks and benefits and may impact patients differentially. Surgery is most often the first line therapy but up to $68 \%$ of patients have persistent disease or incomplete remission necessitating further treatment after surgery [24]. Medical therapy with either a mono or a combination therapy is used when remission is not achieved surgically. Somatostatin analogs are most often used as monotherapy while GH receptor antagonists and dopamine agonists are usually employed in combination therapy. Radiation treatment is usually reserved for resistant GH excess but this may also need to be combined with other medical therapies to achieve remission (TABLE 1).

\section{Precision medicine in acromegaly}

Initiating precision medical therapy based on specific biomarkers is becoming an achievable option for enhancing outcomes [72]. Detailed tumor histology can now provide quantification of somatostatin receptor subtype expression; describe the ratio of receptor expression; identify associated expression of proteins, such as AI expression of aryl hydrocarbon-interacting protein (AIP), beta arreston-1; quantify the percentage of markers of proliferative activity such as Ki-67 antigen and p53 [73]; and describe tumor granulation pattern, all of which have the potential to provide some guidance in predicting a patients response or resistance to a specific SSA, identifying monitoring intervals and directing more individualized therapy. Likewise, the identification of specific genomic polymorphisms has the potential to predict response to and liver abnormalities associated with pegvisomant $[74,75]$ and the identification of tumor dopamine receptors can help predict response to dopamine agonist. Soluble Klotho (sKlotho), a protein which inhibits insulin and IGF-1 signaling has been found to be significantly elevated in patients with acromegaly [76] and may represent a new clinical and molecular disease biomarker [77,78]. In the future, more targeted disease treatments and monitoring may be improved with the discovery of new disease biomarkers.

\section{Potential improvement in acro- megaly drug therapy - Emerging treatment modalities}

The development of SSAs (octreotide and lanreotide) and an SSA with a broader spectrum of activity (pasireotide) has greatly improved treatment outcomes. The availability of longacting SSAs addressed patient preference for reducing the need for daily injections and in some cases, permitting home administration of SSAs [79]. The future development of SSAs with 


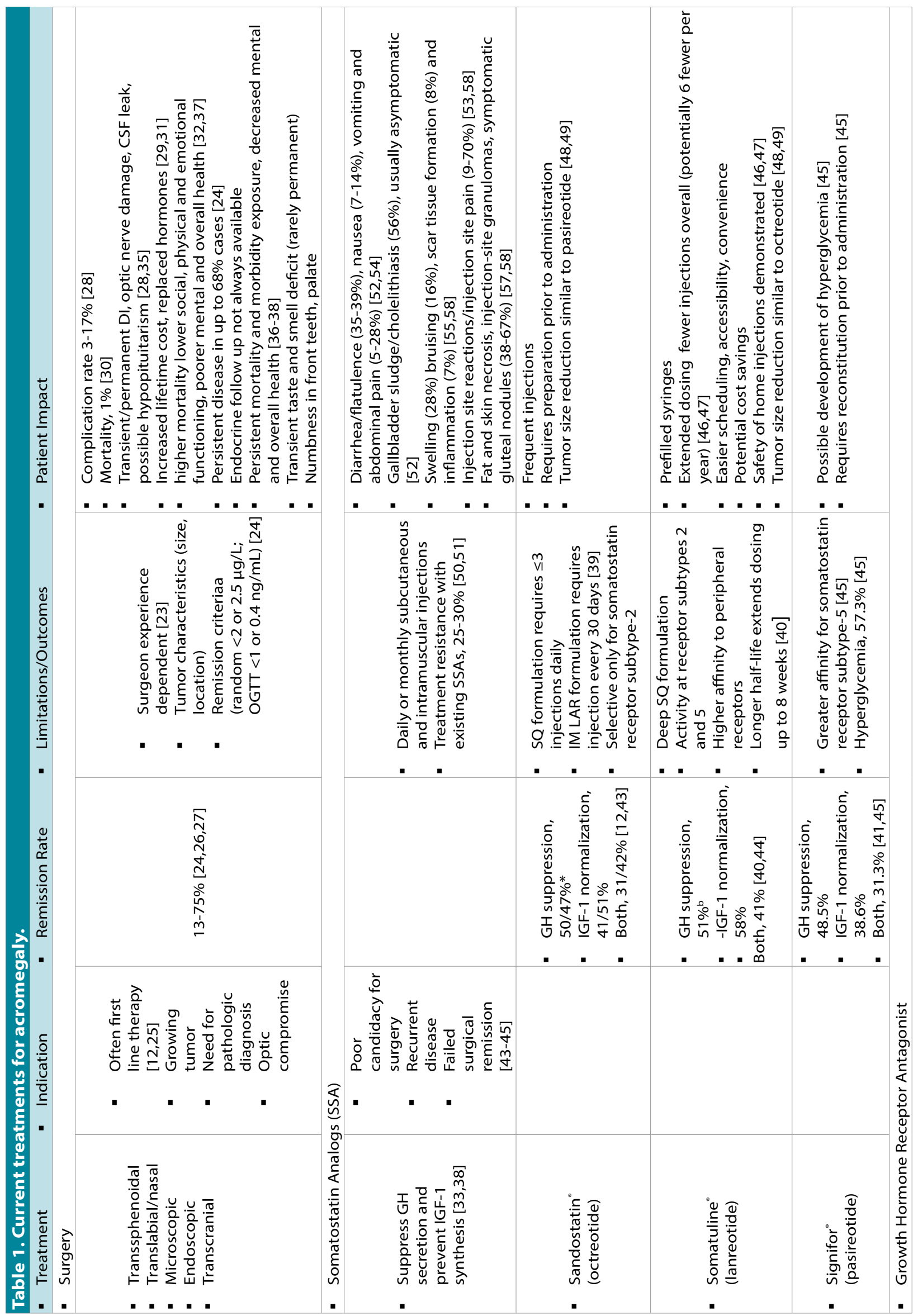




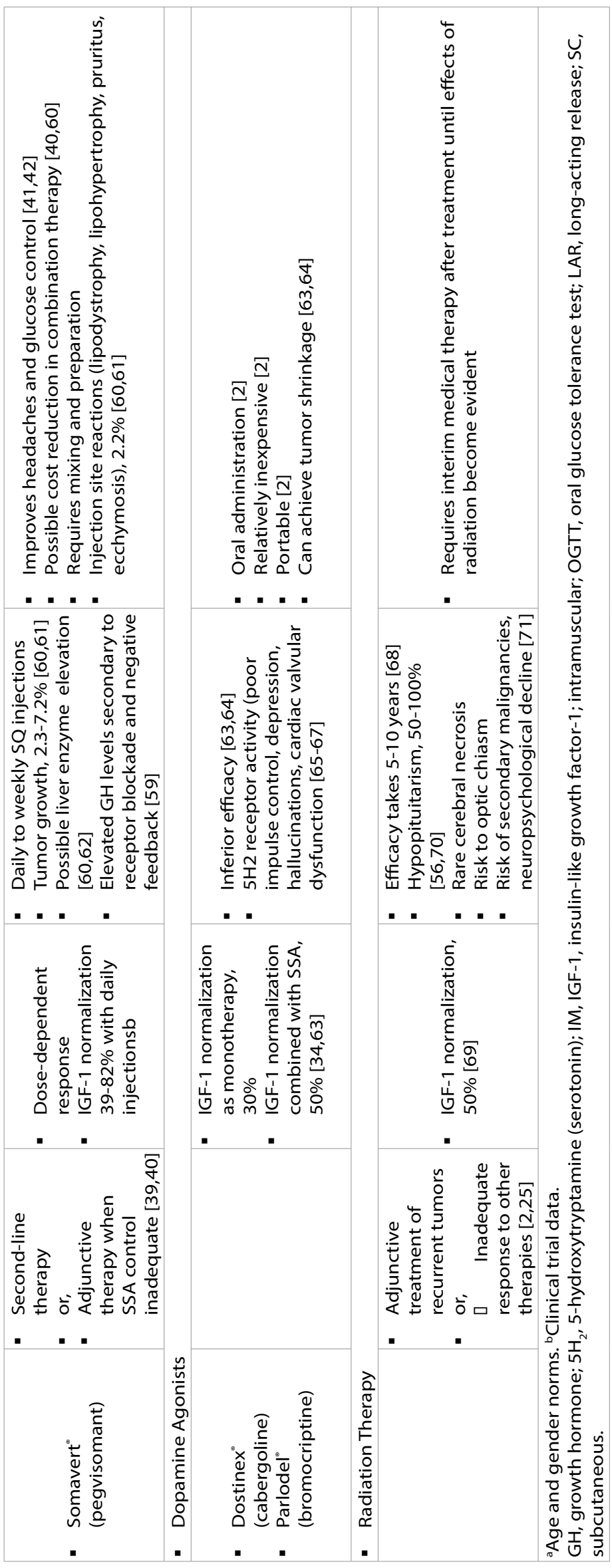


a greater range of activity may further decrease the incidence of treatment failures [80].

A new formulation of subcutaneous depot octreotide not currently commercially available is based on crystalline technology which provides 4-5 times the bioavailability of octreotide LAR with more rapid IGF-suppression in healthy volunteers [81]. In a phase 1 pharmacokinetic study, the release of subcutaneous octreotide depot was sustained for up to 4 weeks. The reported safety profile was similar to other SSAs. A subcutaneous octreotide hydrogel implant containing pelletized octreotide within a hydrogel capsule has been shown to provide continuous, systemic release of octreotide for over 6 months; however, the current status of this product is unknown.

Ideally, parenteral medications will be replaced or supplemented with oral medications. In addition to eliminating painful injections and improving patient convenience the use of oral medications is likely to result in patient benefits which similar to those that have been demonstrated in other chronic diseases. A parallel to this is the replacement of intravenous deferoxamine with oral deferasirox for the treatment of iron overload disorders resulted in improved compliance with therapy [82] with superior clinical outcomes [83], enhanced quality of life [84] and pharmacoeconomic benefits [85].

A new octreotide formulation uses novel Transient Permeability Enhancer ${ }^{\circ}$ technology which permits the transient paracellular passage of octreotide across the gastrointestinal wall in the small intestines via tight junctions [86]. A recent phase 3 trial demonstrated the safety and efficacy of oral octreotide capsules (Octreolin $^{\circledR}$ Mycapssa ${ }^{\mathrm{Tm}}$; Chiasma, Inc. NCT01412424) administered twice-daily [87]. During treatment with oral octreotide, most GH levels were reduced and acromegaly-related symptoms improved. Among 151 evaluable subjects initiating oral octreotide, $65 \%$ achieved the primary endpoint of IGF-1 $<1.3 \mathrm{x}$ upper limit of normal and mean integrated $\mathrm{GH}<2.5$ $\mathrm{ng} / \mathrm{mL}$ at the end of the 7 -month treatment period. Among subjects who entered a 6-month extension phase, $85 \%$ maintained this response up to 13 months demonstrating treatment durability.

\section{Factors impacting the success of surgical and medical therapies}

Multiple factors contribute to outcomes in addition to or in conjunction with the selection of medical therapies and deserve consideration in treatment planning.

\section{Follow up}

Rigorous follow-up is important to successfully achieve treatment goals, reduce morbidity and return mortality rates to population norms. Treatment guidelines outline the need for regular monitoring of $\mathrm{GH}$ and IGF-1 as indicators of disease control, imaging tumor activity and other indicators of associated co-morbidity remission [22]. Successfully initiating treatment and maintaining compliance is multifactorial and appears to be enhanced by using a team approach that actively involves patients, nurses, and physicians as equal partners in the treatment process [63]. Additionally, improved clinical outcomes might be achieved by defining optimal timing intervals for each class of medical therapy used and implementing strategies to identify recurrent disease and prevent loss of patients to followup [64]. The proximity of care providers to the patients home and transportation issues may need to be considered particularly if the patient is significantly disabled. Coordination of the patient and providers schedules to enable the patient to maintain work responsibilities particularly when frequent absences for monitoring or treatment are required can inhibit treatment adherence. Kasuki et al. reported patients most often failed to follow up, despite poor disease control when they were not experiencing disease symptoms, failing to understand the complexity of their disease [4].

\section{Quality of life factors}

Not surprisingly, lack of symptom control has a significant negative impact on quality of life measures [88]. Health-related decreases in quality of life was assessed in a large U.S. survey $(\mathrm{N}=7,557)$ in which respondents placed greatest value on avoiding anxiety, depression, sleep disturbance and loss of physical function. Patients report pain as having a significant negative impact on quality of life, even more so than fatigue or the social impact of acromegaly [89]. For patients with acromegaly, poor sleep quality and sleep apnea was associated with a greater incidence of subclinical and clinical depression [90] and anxiety [91], lowering quality of life $[90,91]$. Sleep disturbance also occurs in association with pain (headaches, arthralgias, myalgias and vertebral fractures) and treatment-related anxiety contributes to fatigue, 
poor motivation and depression in these patients $[9,10,92,93]$. Symptoms often persist despite normalization of IGF-1 $[47,94]$ which can affect the patient's physical ability to adhere to a long term plan of care. Also, diminished quality of life may persist long after achieving biochemical control of the disease due to physical changes that do not return to normal $[14,95]$.

The quality of life among patients with acromegaly treated with surgery alone is higher than those requiring life-long medications [96], suggesting that both lack of disease control and treatment-related symptoms have negative effects on post-operative quality of life. Similarly, patients treated with medication have worse disease specific quality of life than patients achieving surgical remission [97].

Neurocognitive changes in executive function, short term memory and concentration may improve with treatment but often persist to some degree despite pharmacotherapy [92,98100]. Treatment with radiation therapy is associated with hypopituitarism and diminished quality of life and often enhances neurocognitive dysfunction [101,102]. Neurocognitive changes may impact the patient's ability to consistently follow through on a treatment protocol and may necessitate multiple forms of education and reinforcement to achieve treatment adherence.

\section{- Drug administration issues}

A systematic review of 26 studies evaluating the importance of convenience in patient health care, independent of outcomes, revealed the most highly valued aspects were mode of treatment administration ( $\mathrm{n}=11,42 \%)$ and physical location of treatment $(\mathrm{n}=6$; 23\%) [103]. Specifically, patients valued oral methods of medication administration, less frequent injections and pre-filled injectable preparations that saved administration time [103]. Additionally, where patients viewed the possibility of avoiding negative outcomes, they favored more frequent screening visits but generally preferred local treatment centers that minimized travel. Patients also reported a clear preference for treatments that could be administered at home [103].

In a survey of patients with controlled and uncontrolled acromegaly, less frequent visits contribute to higher satisfaction [104]. Subjects treated with combination were less satisfied than patients receiving monotherapy. The time since diagnosis and the duration of medical therapy were positively correlated with treatment effectiveness. Quality of life scores were also positively correlated with perceived treatment efficacy decreased adverse events, convenience and global satisfaction. In contrast, depression scores were inversely correlated to these aspects [104].

\section{Economic factors}

Healthcare resource utilization, and consequently the cost of care, is increased in patients with acromegaly associated with multiple comorbidities [79]. Cardiovascular complications alone can nearly triple the odds of hospitalization [79]. Early identification and appropriate disease management may reduce health care cost associated with diabetes, acromegaly-related cancers, bone and joint disease, cardiovascular disease, while improving patient functioning and productivity $[105,106]$.

The use of SSAs is the biggest driver of healthcare costs among patients with acromegaly [106]. Surgical cure is the most cost-effective treatment; however, when this is not achievable because of poor patient candidacy or failed resection, other therapies such as SSAs are required for disease control [107]. Among SSAs, lanreotide has been reported as more economical for health care payers and more convenient for physicians and patients because of lower risk of needle clogging and the possibility of longer intervals between injections [108] while providing efficacy comparable to octreotide [109].

Travel costs for treatment, time lost in work related medical leave and absences, job loss secondary to cognitive and physical disabilities have not been quantified for this patient population.

\section{Patient-reported injection related issues}

Anecdotally, patients report difficulty arranging injections around work schedules, family events and vacations, particularly when associated with disruptive side effects, such as diarrhea [110]. Both disease- and treatmentrelated issues have been reported to create family conflict. Consequently, injection intervals are often extended or shortened to accommodate these issues. Some patients report 'break through' symptoms at the end of an injection cycle and may either shorten the treatment cycle or require a second injection of a short-acting suppressive agent. Medical management may 
be interrupted by supply shortages, insurance authorization difficulties or the availability of a health care provider to administer the injection.

Treatment location may require travel with a significant economic outlay due to disrupted work schedules [110] and possibly interfering with medication monitoring and compliance. The need for ongoing injections can represent a constant psychological reminder of a state of illness, adding a sense of having lack of control and loss of individual identity by becoming a patient [22]. Cognitive changes in older patients can cause learning difficulties, enlarged hands make it difficult to manipulate administration devices and visual deficits or presbyopia can make preparation and self-administering injectable medications challenging. Patients need to develop confidence in persons administering their injections. Patients report feeling greater injection discomfort and more break-through symptoms when faced with an unfamiliar nurse, or a nurse lacking knowledge in the preparation and administration of their SSA injection.

\section{- Treatment compliance and adherence considerations}

Although the terms adherence and compliance are frequently used interchangeably, they are not often defined in the literature and there is no gold standard for their measurement [111]. Compliance, infers yielding to an external source whereas adherence suggests an internal commitment. The definition of adherence adopted by the World Health Organization's Adherence Project with respect to long-term therapy is: the extent to which a person's behavior with respect to taking medications, following a diet, and/or executing lifestyle changes, corresponds with agreed recommendations from a health care provider [112]. The mean rate of adherence to longterm therapy for chronic illness in developed countries is estimated at approx. 50\% and even less elsewhere. Promoting adherence and patient commitment to long term therapy is critical to patient outcomes yet challenging as no one intervention is appropriate for all patients in all circumstances. The concept of person-centered care emerged as a means of refocusing health care with the patient as an equal partner in care decisions in order to achieve the best outcomes. Central to this are the principles as described by the Picker Institute including: respect for patients' values, preferences and expressed needs; coordination and integration of care; information, communication and education; physical comfort; emotional support and alleviation of fear and anxiety; involvement of family and friends; transition and continuity [113]. Patient centered care required the involvement and integration of all members of the health care team.

Poor adherence to a prescribe medical therapy includes not filling prescriptions, not taking doses as prescribed or at non therapeutic dosing intervals, stopping treatment prematurely or to accommodate life events and failing to participate in clinic follow-up visits [114]. The extent to which the patient chooses or is able to follow a prescribed treatment regimen is influenced by many factors, many of which have been described in the narrative above; however, adherence and patient compliance decision making generally remains poorly understood [115], particularly in relation to patients with acromegaly. A recent study of acromegaly registry patients in Germany concluded that the major reason for poor control of acromegaly was poor patient motivation, and increased efforts for patient education was recommended [116]. This was supported by the findings in the ACROSPECT study were $21 \%$ of patients failed to follow up because they lacked understanding of the necessity [5]; however, despite these issues, in a recent survey of 126 US endocrinologists, only 50\% felt that treatment adherence affected patient outcomes [117].

\section{Provider-related issues}

Among nurses interviewed in one study $(\mathrm{N}=77)$, 68\% reported having never received special training on the injection of SSAs [101]. Boyd and colleagues (2013) demonstrated the efficacy of teaching nurses administration techniques by evaluating IM injection accuracy using computed tomography [118]. Improved injection placement also correlated with patients reported improvement in symptom control. Teaching technique and providing feedback improved accuracy by $22-38 \%$, depending on patient body mass index. Ease of preparation and administration of injections are reported to be highly valued by nurses [101]; however, numerous problems have been reported with the use of injection devices. Poor visibility of the medication in the device, incomplete mixing of the medication and diluent, variable sturdiness of device plungers, and clogging needles affect nurse confidence that all the medication has been delivered $[101,119]$. 
In the author's experience the use of SSAs in the US requires time-consuming insurance authorization and problem-solving regarding medication supply issues by nursing staff. Denied insurance coverage may necessitate peer-to-peer interactions with insurance representatives unfamiliar with the diagnosis and treatment of acromegaly. The time commitment by clinic and nursing staff can be considerable. This may not be feasible in small or rural clinics.

SSAs must be refrigerated with appropriate equipment to avoid waste of expensive medications. This is as much a concern with home delivery and administration as it is for office-based treatment. In medical offices unable to provide the required on-site drug storage, timing drug delivery can make coordinating appointments difficult for patients and staff. Onsite storage comes with specific requirement for temperature monitoring and medication security.

In a survey of 23 providers, Lui et al. found all providers reported side effects as the most substantial burden (100\%), followed by financial issues (89\%) and the therapy being too complicated or inconvenient to patients (56\%) [119]. Injection site issues such as pain were cited as a significant side effect with up to $70 \%$ noting that patients reported worsening symptoms at the end of the dosing interval.

\section{Conclusion}

The choice of treatment that minimizes patient burdens and maximizes benefits is a key component to promoting treatment adherence and improved treatment outcomes in acromegaly. Early disease identification and prompt treatment minimize comorbidities and promise the best outcomes, and may offset the overall cost of therapy.
Developments in precision medicine and new treatment modalities may require detailed histopathology in centers that perform larger volumes of pituitary tumor resections; however, when long term or lifelong treatment is indicated, designing a treatment plan to promote adherence becomes challenging. Establishing with the patient meaningful, achievable quality of life goals may provide a basis for the development of an attainable treatment program.

Promoting adherence requires the patient to have a thorough understanding of the disease, its impact and evolution across the life cycle in the context of their specific life goals and life situation. Patients are more likely to adhere to a treatment regimen when they can be selfadministered, they perceive treatment as a means to avoid negative outcomes or perceive positive effects with fewer side effects from therapy. New therapies based on longer dosing intervals and especially if orally administered can improve quality of life and may also help to decrease patient and provider burdens associated with long-term therapies. Follow up for medical monitoring and therapy adjustments is necessary but intrusive and may require flexibility or a paradigm shift from traditional clinic visits.

Establishing a viable treatment program requires coordination of the attending physician, nurse and the patient, early involvement of the patient's local and primary health care teams. Dynamic adjustments may be indicated over the life of a patient with acromegaly in order to maintain disease control.

\section{Acknowledgments}

The authors acknowledge the editorial assistance of Dr. Carl S. Hornfeldt, Apothekon, Inc., with funding provided by Chiasma, Inc., Waltham, MA. 


\section{REFERENCES}

Chanson P, Salenave S. Acromegaly. Orphanet. J. Rare Dis. 3, 17 (2008).

Katznelson L, Laws ER Jr, Melmed S, et al. Acromegaly, an endocrine society clinical practice guideline. J. Clin. Endocrinol. Metab. 99(11), 39333951(2014).

Holdaway IM, Rajasoorya C. Epidemiology of acromegaly. Pituitary. 2(1), 29-41 (1999).

Kasuki L, Marques NV, Nuez MJ, et al. Acromegalic patients lost to follow-up, a pilot study. Pituitary. 16(2), 245-250 (2013).

Delemer B, Chanson P, Foubert L, et al. Patients lost to follow-up in acromegaly, results of the ACROSPECT study. Eur. J. Endocrinol. 170(5), 791-797 (2014).

Burton T, Le Nestour E, Bancroft T, Neary M. Real-world comorbidities and treatment patterns of patients with acromegaly in two large US health plan databases. Pituitary. 16(3), 354362 (2013).

Ben-Shlomo A, Melmed S. Skin manifestations in acromegaly. Clin. Dermatol. 24, 256-259 (2006).

Capatina C, Wass JA. 60 Years of neuroendocrinology. acromegaly. $J$. Endocrinol. 226, T141-160 (2015).

Nachtigall L, Delgado A, Swearingen B, et al. Changing patterns in diagnosis and therapy of acromegaly over two decades. J. Clin. Endocrinol. Metab. 93, 2035-2041 (2008).

Chanson P, Salenave S, Kamenicky P. Acromegaly. Handb. Clin. Neurol. 124, 197-219 (2014).

Melmed S, Casanueva FF, Klibanski A, et al. A consensus on the diagnosis and treatment of acromegaly complications. Pituitary. 16(3), 294302 (2013).

Lely AJ, Beckers A, Daly A, Lamberts SW, Clemmons DR. Acromegaly, Pathology, Diagnosis and Treatment. Boca Raton, FL Taylor and Francis (2005).
Anagnostis P, Efstathiadou ZA, Charizopoulou M, et al. Psychological profile and quality of life in patients with acromegaly in Greece. Is there any difference with other chronic diseases? Endocrine. 47, 564-571(2014).

Imran SA, Tiemensma J, Kaiser SM, et al. Morphometric changes correlate with poor psychological outcomes in patients with acromegaly. Eur. J. Endocrinol. 174, 41-50 (2016).

Pantanetti P, Sonino N, Arnaldi G, Boscaro M. Self-image and quality of life in acromegaly. Pituitary. 5, 17-19 (2002).

Colao A, Vandeva S, Pivonello R, et al. Could different treatment approaches in acromegaly influence life expectancy? A comparative study between Bulgaria and Campania (Italy). Eur. J. Endocrinol. 171, 263273 (2014).

Melmed S, Casanueva F, Cavagnini F, et al. Consensus statement, medical management of acromegaly. Eur. J. Endocrinol. 153, 737-740 (2005).

Beauregard C, Truong U, Hardy J, Serri O. Long-term outcome and mortality after transsphenoidal adenomectomy for acromegaly. Clin. Endocrinol. (Oxf). 58, 86-91 (2003).

Swearingen B, Barker FG, Katznelson $\mathrm{L}$, et al. Long-term mortality after transsphenoidal surgery and adjunctive therapy for acromegaly. J. Clin. Endocrinol. Metab. 83(10), 3419-3426 (1998).

Găloiu S, Poiană C. Current therapies and mortality in acromegaly. J. Med. Life. 8, 411-415 (2015).

Knutzen R, Ezzat S. The cost of medical care for the acromegalic patient. Pituitary Tumor Network Association.

Gurel MH, Bruening PR, Rhodes C, Lomax KG. Patient perspectives on the impact of acromegaly, results from individual and group interviews. Patient Prefer Adherence. 8, 53-62 (2014).

Danzig J. Acromegaly. BMJ. 335, 824-825 (2007).
Sheaves R, Jenkins P, Blackburn P, et al. Outcome of transsphenoidal surgery for acromegaly using strict criteria for surgical cure. Clin. Endocrinol. (Oxf). 5, 407-413 (1996).

Melmed S. Medical progress, acromegaly. N. Engl. J. Med. 355(24), 2558-2573 (2006).

Ross DA, Wilson CB. Results of transsphenoidal microsurgery for growth hormone-secreting pituitary adenoma in a series of 214 patients. $J$. Neurosurg. 68(6), 854-867 (1988).

Evran M, Sert M, Tetiker T. Clinical experiences and success rates of acromegaly treatment, the single center results of 62 patients. BMC Endocr. Disord. 14, 97 (2014).

$\mathrm{Ku}$ CR, Hong JW, Kim EH, Kim $\mathrm{SH}$, Lee EJ. Clinical predictors of $\mathrm{GH}$ deficiency in surgically cured acromegalic patients. Eur. J. Endocrinol. 171(3), 379-387 (2014).

Sanyal D, Raychaudhuri M. Outcome in acromegaly, a retrospective analysis. Indian J. Endocrinol. Metab. 16(Suppl 2), S291-S293 (2012).

Laws ER. Complications of transsphenoidal surgery. In, Samii M, editor. Surgery of the Sellar Region and Paranasal Sinuses. Berlin, Springer (1991).

Brada M, Ashley S, Ford D, et al. Cerebrovascular mortality in patients with pituitary adenoma. Clin. Endocrinol. (Oxf). 57(6), 713-717 (2002).

Erfurth EM, Bülow B, Svahn-Tapper G, et al. Risk factors for cerebrovascular deaths in patients operated and irradiated for pituitary tumors. J. Clin. Endocrinol. Metab. 87(11), 4892-4899 (2002).

Laws ER, Wong JM, Smith TR, et al. A checklist for endonasal transsphenoidal anterior skull base surgery. J Neurosurg. 30, 1-6 (2015).

Ghatge SB, Modi DB. Treatment of ruptured ICA during transsphenoidal surgery. Two different endovascular strategies in two cases. Interv. 
Neuroradiol. 16(1), 31-37 (2010).

Burman P, Mattsson AF, Johannsson G, et al. Deaths among adult patients with hypopituitarism, hypocortisolism during acute stress, and de novo malignant brain tumors contribute to an increased mortality. J. Clin. Endocrinol. Metab. 98(4), 1466-1475 (2013).

Bates AS, Van't Hoff W, Jones PJ, Clayton $\mathrm{RN}$. The effect of hypopituitarism on life expectancy. J. Clin. Endocrinol. Metab. 81(3), 1169-1172 (1996).

Hakkaart-van Roijen L, Stevenaert A, Busschback J, van Eijk W, Rutten F. The burden of hypopituitarism after pituitary surgery. Endocrinol. Metab. 4(Suppl B), 139-142 (1997).

Murray RD, Kim K, Ren SG, et al. Central and peripheral actions of somatostatin on the growth hormone-IGF-I axis. J. Clin. Invest. 114(3), 349-356 (2004).

Muhammad A, van der Lely AJ, Neggers SJ. Review of current and emerging treatment options in acromegaly. Neth. J. Med. 73(8), 362-367 (2015).

Neggers SJ, van der Lely AJ. Combination treatment with somatostatin analogues and pegvisomant in acromegaly. Growth Horm. IGF Res. 21, 129-133 (2011).

Schreiber I, Buchfelder M, Droste M, et al. Treatment of acromegaly with the $\mathrm{GH}$ receptor antagonist pegvisomant in clinical practice, safety and efficacy evaluation from the German Pegvisomant Observational Study. Eur. J. Endocrinol. 156(1), 75-82 (2007).

Higham CE, Chung TT, Lawrance J, Drake WM, Trainer PJ. Long-term experience of pegvisomant therapy as a treatment for acromegaly. Clin. Endocrinol. (Oxf). 71(1), 86-91 (2009).

Sandostatin ${ }^{\ominus}$ LAR Depot (octreotide acetate for injectable suspension). Prescribing Information. Novartis Pharmaceuticals Corporation East Hanover, NJ.

Somatuline ${ }^{\oplus}$ Depot (lanreotide) Injection. Prescribing Information. Ipsen
Biopharmaceuticals, Inc., Basking Ridge, NJ.

Signifor ${ }^{\bullet}$ LAR (pasireotide) for injectable suspension for intramuscular use. Prescribing Information. Novartis Pharmaceuticals Corporation, East Hanover, NJ.

Salvatori R, Nachtigall LB, Cook DM, et al. Effectiveness of self- or partneradministration of an extended-release aqueous-gel formulation of lanreotide in lanreotide-naïve patients with acromegaly. Pituitary. 13(2), 115-122 (2010).

Salvatori R, Woodmansee WW, Molitch M, Gordon MB, Lomax KG. Lanreotide extended-release aqueousgel formulation, injected by patient, partner or healthcare provider in patients with acromegaly in the United States, 1-year data from the SODA registry. Pituitary. 17(1), 1321 (2014).

Colao A, Bronstein MD, Freda P GF, et al. Pasireotide versus octreotide in acromegaly, a head-to-head superiority study. J. Clin. Endocrinol. Metab. 99(3), 791-799 (2014).

Ben-Shlomo A. Pharmacotherapy for acromegaly, future role for pasireotide? Endocrinol. Metab. Clin. North Am. 44(1), 35-41 (2015).

Casarini AP, Jallad RS, Pinto EM, et al. Acromegaly, correlation between expression of somatostatin receptor subtypes and response to octreotidelar treatment. Pituitary. 12, 297-303 (2009).

Colao A, Auriemma RS, Lombardi G, Pivonello R. Resistance to somatostatin analogs in acromegaly. Endocr. Rev. 32(2), 247-271 (2011).

Grasso LF, Auriemma RS, Pivonello R, Colao A. Adverse events associated with somatostatin analogs in acromegaly. Expert Opin. Drug Saf. 14(8), 1213-1226 (2015).

Chanson P, Leselbaum A, Blumberg J, Schaison G. Efficacy and tolerability of the long-acting somatostatin analog lanreotide in acromegaly. A 12-month multicenter study of 58 acromegalic patients. Pituitary. 2(4), 269-276 (2000).

Verhelst JA, Pedroncelli AM, Abs R, et al. Slow-release lanreotide in the treatment of acromegaly: a study in 66 patients. Eur. J. Endocrinol. 143(5), 577-584 (2000).

Burman P, Besjakov J, Svensjö T. Large fat and skin necroses after deep subcutaneous injections of a slowrelease somatostatin analogue in a woman with acromegaly. Growth Horm. IGF Res. 20(6), 438-440 (2010).

Caron P, Cogne M, Raingeard I, BexBachellerie V, Kuhn JM. Effectiveness and tolerability of 3-year lanreotide Autogel treatment in patients with acromegaly. Clin. Endocrinol. 64(2), 209-214 (2006).

Debono M, Hon LQ, Bax N, Blakeborough A, Newell-Price J. Gluteal nodules in patients with metastatic midgut carcinoid disease treated with depot somatostatin analogs. J. Clin. Endocrinol. Metab. 93(5), 1860-1864 (2008).

Strasburger CJ, Karavitaki N, Störmann $S$, et al. Patient-reported outcomes of parenteral somatostatin analogue injections in 195 patients with acromegaly. Eur. J. Endocrinol. 174(3), 355-362 (2016).

Lely AJ, Hutson RK, Trainer PJ, et al. Long-term treatment of acromegaly with pegvisomant, a growth hormone receptor antagonist. Lancet. 358(9295), 1754-1759 (2001).

Lely AJ, Biller BM, Brue T, et al. Long-term safety of pegvisomant in patients with acromegaly: comprehensive review of 1288 subjects in ACROSTUDY. $J$. Clin. Endocrinol. Metab. 97(5), 15891597 (2012).

Buchfelder M, Schlaffer S, Droste M, et al. The German ACROSTUDY: past and present. Eur. J. Endocrinol. 161(Suppl 1), S3-S10 (2009).

Manavela MP, Danilowicz K, Bruno OD. 
Skin reaction and fever after treatment with pegvisomant in a patient with acromegaly. Clin. Ther. 32(2), 246249 (2010).

Manjila S, Wu OC, Khan FR, et al. Pharmacological management of acromegaly: a current perspective. Neurosurg. Focus. 29(4), E14 (2010).

Abs R, Verhelst J, Maiter D, et al. Cabergoline in the treatment of acromegaly: a study in 64 patients. $J$. Clin. Endocrinol. Metab. 83(2), 374378 (1998).

Colao A, Ferone D, Marzullo P, et al. Effect of different dopaminergic agents in the treatment of acromegaly. J. Clin. Endocrinol. Metab. 82, 518523 (1997).

Zanettini R, Antonini A, Gatto G, et al. Valvular heart disease and the use of dopamine agonists for Parkinson's disease. N. Engl. J. Med. 356(1), 39-46 (2007).

Bancos I, Nannenga MR, Bostwick JM, et al. Impulse control disorders in patients with dopamine agonist-treated prolactinomas and nonfunctioning pituitary adenomas: a case-control study. Clin. Endocrinol. 80(6), 863868 (2014).

Welsh L, Ajithkumar T, Brada M. Radiotherapy for Pituitary and Hypothalamic Tumours. Endotext [Internet]. South Dartmouth, MA: MDText.com, Inc; 2000-2013.

Loeffler JS, Shih HA. Radiation therapy in the management of pituitary adenomas. J. Clin. Endocrinol. Metab. 96(7), 1992-2003 (2011).

Fernandez A, Brada M, Zabuliene L, Karavitaki N, Wass JA. Radiationinduced hypopituitarism. Endocr. Relat. Cancer. 16(3), 733-772 (2009).

Becker G, Kocher M, Kortmann RD, et al. Radiation therapy in the multimodal treatment approach of pituitary adenoma. Strablenther Onkol. 178(4), 173-186 (2002).

Silverstein JM. Need for improved monitoring in patients with acromegaly. Endocrine Connections.
4(4), R59-67 (2015).

Alimohamadi M, Ownagh V, Mahouzi L, et al. The impact of immunohistochemical markers of Ki67 and p53 on the long-term outcome of growth hormone-secreting pituitary adenomas: A cohort study. Asian J. Neurosurg. 9(3), 130-136 (2014).

Bernabeu I, Marazuela M, Lucas T, et al. Pegvisomant-induced liver injury is related to the UGT1A1*28 polymorphism of Gilbert's syndrome. J. Clin. Endocrinol. Metab. 95(5), 2147-2154 (2010).

Bernabeu I, Alvarez-Escolá C, Quinteiro $\mathrm{C}$, et al. The exon 3-deleted growth hormone receptor is associated with better response to pegvisomant therapy in acromegaly. J. Clin. Endocrinol. Metab. 95(1), 222-229 (2010).

Sze L, Bernays RL, Zwimpfer C, et al. Excessively high soluble Klotho in patients with acromegaly. J. Intern. Med. 272(1), 93-97 (2012).

Kohler S, Tschopp O, Sze L, et al. Monitoring for potential residual disease activity by serum insulin-like growth factor 1 and soluble Klotho in patients with acromegaly after pituitary surgery: is there an impact of the genomic deletion of exon 3 in the growth hormone receptor (d3-GHR) gene on "safe" GH cut-off values? Gen. Comp. Endocrinol. 188(1), 282-287 (2013).

Varewijck AJ, van der Lely AJ, Neggers SJ, et al. In active acromegaly, IGF1 bioactivity is related to soluble Klotho levels and quality of life. Endocr. Connect. 3(2), 85-92 (2014).

Broder MS, Neary MP, Chang E, Cherepanov D, Katznelson L. Treatments, complications, and healthcare utilization associated with acromegaly: a study in two large United States databases. Pituitary. 17(4), 333-341 (2014).

Alvarez O, Rodriguez-Cortes $\mathrm{H}$, Robinson $\mathrm{N}$, et al. Adherence to deferasirox in children and adolescents with sickle cell disease during 1-year of therapy. $J$. Pediatr. Hematol. Oncol. 31, 739-744
(2009)

Rofail D, Abetz L, Viala M, et al. Satisfaction and adherence in patients with iron overload receiving iron chelation therapy as assessed by a newly developed patient instrument. Value Health. 12, 109-117 (2009).

Jordan LB, Vekeman F, Sengupta A, et al. Persistence and compliance of deferoxamine versus deferasirox in Medicaid patients with sickle-cell disease. J. Clin. Pharm. Ther. 37, 173181 (2012).

Cappellini MD, Bejaoui M, Agaoglu L, et al. Prospective evaluation of patientreported outcomes during treatment with deferasirox or deferoxamine for iron overload in patients with betathalassemia. Clin. Ther. 29(5), 909917 (2007).

Porter J, Bowden DK, Economou M, et al. Health-related quality of life, treatment satisfaction, adherence and persistence

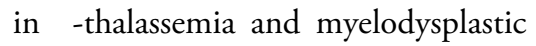
syndrome patients with iron overload receiving deferasirox: results from the EPIC clinical trial. Anemia. 297641 (2012).

Imran F, Phatak P. Pharmacoeconomic benefits of deferasirox in the management of iron overload syndromes. Expert Rev. Pharmacoecon. Outcomes Res. 9(4), 297-304 (2009).

Tuvia S, Pelled D, Marom K, et al. A novel suspension formulation enhances intestinal absorption of macromolecules via transient and reversible transport mechanisms. Pharm. Res. 31, 2010-2021 (2014).

Melmed S, Popovic V, Bidlingmaier M, et al. Safety and efficacy of oral octreotide in acromegaly: results of a multicenter phase III trial. J. Clin. Endocrinol. Metab.100(4), 1699-1708 (2015).

Vandeva S, Yaneva M, Natchev E, et al. Disease control and treatment modalities have impact on quality of life in acromegaly evaluated by Acromegaly Quality of Life (AcroQoL) Questionnaire. Endocrine. 49(3), 774782 (2015).

Craig BM, Reeve BB, Brown PM, et al. 
US valuation of health outcomes measured using the PROMIS-29. Value Health. 17(8), 846-853 (2014).

Leistner SM, Klotsche J, Dimopoulou $\mathrm{C}$, et al. Reduced sleep quality and depression associate with decreased quality of life in patients with pituitary adenomas. Eur. J. Endocrinol. 172, 733-743 (2015).

Geraedts VJ, Dimopoulou C, Auer M, et al. Health outcomes in acromegaly: depression and anxiety are promising targets for improving reduced quality of life. Front Endocrinol. (Lausanne). 5, 229 (2015).

Szcześniak D, Jawiarczyk-Przybyłowska A, Rymaszewska J. The quality of life and psychological, social and cognitive functioning of patients with acromegaly. Adv. Clin. Exp. Med. 24(1), 167-172 (2015).

Biermasz NR, van Thiel SW, Pereira AM, et al. Decreased quality of life in patients with acromegaly despite longterm cure of growth hormone excess. J. Clin. Endocrinol. Metab. 89(11), 5369-5376 (2004).

Biermasz NR, Pereira AM, Smit JW, Romijn JA, Roelfsema F. Morbidity after long-term remission for acromegaly: persisting joint-related complaints cause reduced quality of life. J. Clin. Endocrinol. Metab. 90(5), 2731-2739 (2005).

Tiemensma J, Pereira AM, Romijn JA. Persistent negative illness perceptions despite long-term biochemical control of acromegaly: novel application of the drawing test. Eur. J. Endocrinol. 172(5), 583-593 (2015).

Yoshida K, Fukuoka H, Matsumoto R, et al. The quality of life in acromegalic patients with biochemical remission by surgery alone is superior to that in those with pharmaceutical therapy without radiotherapy, using the newly developed Japanese version of the AcroQoL. Pituitary. 18(6), 876-883.

Andela CD, Biermasz NR, Kaptein AA, Pereira AM, Tiemensma J. More concerns and stronger beliefs about the necessity of medication in patients with acromegaly are associated with negative illness perceptions and impairment in quality of life. Growth Horm. IGF Res. 25(5), 219-226 (2015).

Leon-Carrion J, Martin-Rodriguez JF, Madrazo-Atutxa A, et al. Evidence of cognitive and neurophysiological impairment in patients with untreated naive acromegaly. J. Clin. Endocrinol. Metab. 95(9), 4367-4379 (2010).

Yedinak CG, Fleseriu M. Self-perception of cognitive function among patients with active acromegaly, controlled acromegaly, and non-functional pituitary adenoma: a pilot study. Endocrine. 46(3), 585-593 (2014).

Martín-Rodríguez JF, MadrazoAtutxa A, Venegas-Moreno E, et al. Neurocognitive function in acromegaly after surgical resection of $\mathrm{GH}$-secreting adenoma versus naïve acromegaly. PLoS One. 8(4):e60041 (2013).

Adelman DT, Liebert KJ, Nachtigall LB, Lamerson M, Bakker B. Acromegaly: the disease, its impact on patients, and managing the burden of long-term treatment. Int. J. Gen. Med. 6, 31-38 (2013).

Kauppinen-Mäkelin R, Sane T, Sintonen $\mathrm{H}$, et al. Quality of life in treated patients with acromegaly. J. Clin. Endocrinol. Metab. 91(10), 3891-3896 (2006).

Higgins A, Barnett J, Meads C, Singh J, Longworth L. Does convenience matter in health care delivery? A systematic review of conveniencebased aspects of process utility. Value Health.17(8), 877-887 (2014).

Kepicoglu H, Hatipoglu E, Bulut I, et al. Impact of treatment satisfaction on quality of life of patients with acromegaly. Pituitary. 17(6), 557-563 (2014).

Ben-Shlomo A, Sheppard MC, Stephens JM, Pulgar S, Melmed S. Clinical, quality of life, and economic value of acromegaly disease control. Pituitary. 14(3), 284-294 (2011).

Didoni G, Grottol S, Gasco V, Battistini
M, Ferone D, Giusti M, et al. Costof-illness study in acromegalic patients in Italy. J. Endocrinol. Invest. 27(11), 1034-1039 (2004).

Roset M, Merino-Montero S, LuqueRamírez M, et al. Cost of clinical management of acromegaly in Spain. Clin. Drug Investig. 32(4), 235-245 (2012).

Abrams P, Alexopoulou O, Abs R, Maiter D, Verhelst J. Optimalization and cost management of lanreotideAutogel therapy in acromegaly. Eur. J. Endocrinol. 157, 571-577 (2007).

Sowiński J, Sawicka N, Piątek K, Zybek A, Ruchała M. Pharmacoeconomic aspects of the treatment of pituitary gland tumours. Contemp. Oncol. (Pozn). 17(2), 137-143 (2013).

Engel P. Unpublished Market Research Report. The Care of Acromegaly Patients. Engage Health, Inc., Eagan, MN (2014).

Vermeire E, Hearnshaw H, Van Royen P, Denekens J. Patient adherence to treatment: three decades of research. A comprehensive review. J. Clin. Pharm. Ther. 26(5), 331-342 (2001).

Sabaté E. Adherence to long-term therapies: evidence for action. World Health Organization. Geneva , Switzerland 2003.

Picker Institute. Picker Institute's Eight Principles of Patient-Centered Care. http://cgp.pickerinstitute.org/?page_ id=1319. Accessed 23 October 2017.

Jin J, Sklar GE, Oh VMS, Li SC. Factors affecting therapeutic compliance: A review from the patient's perspective. Ther. Clin. Risk. Manag. 4(1), 269-286 (2008).

Donovan JL. Patient decision making. The missing ingredient in compliance research. Int. J. Technol. Assess. Health Care. 11(3), 443-455 (1995).

Schöfl C, Grussendorf M, Honegger $\mathrm{J}$, et al. Failure to achieve disease control in acromegaly: cause analysis by a registry-based survey. Eur. J. Endocrinol. 172(4), 351-356 (2015).

Polanco-Briceno S, Glass D, Plunkett 
C. Communication practices and awareness of resources for acromegaly patients among endocrinologists. Patient Prefer Adherence. 10, 25312541 (2016).

Boyd AE, DeFord LL, Mares JE, et al. Improving the success rate of gluteal intramuscular injections. Pancreas. 42(5), 878-882 (2013).

Liu S, Xu Y, Begelman SM, Shi L. Barriers to Treatment adherence associated with acromegaly in the United States: provider's perspective. Value Health. 18, A1-307 (2015).

Fleseriu M. Advances in the pharmacotherapy of patients with acromegaly. Discov. Med. 17(96), 329338 (2014).

Tiberg F, Roberts J, Cervin C, et al. Octreotide s.c. depot provides sustained octreotide bioavailability and similar IGF-1 suppression to octreotide LAR in healthy volunteers. Br. J. Clin. Pharmacol. 80(3), 460-472 (2015).

Chieffo C, Cook D, Xiang Q, Frohman LA. Efficacy and safety of an octreotide implant in the treatment of patients with acromegaly. J. Clin. Endocrinol. Metab. 98(10), 4047-4054 (2013).

Gadelha MR, Chieffo C, Bai SA, Hu $\mathrm{X}$, Frohman LA. A subcutaneous octreotide hydrogel implant for the treatment of acromegaly. Endocr. Pract. 18, 870-881 (2012).

Osborne RH, De Abreu Lourenço R, Dalton A, et al. Quality of life related to oral versus subcutaneous iron chelation: a time trade-off study. Value Health. 10(6), 451-456 (2007).
Delea TE, Sofrygin O, Thomas SK, et al. Cost effectiveness of once-daily oral chelation therapy with deferasirox versus infusional deferoxamine in transfusion-dependent thalassaemia patients: US healthcare system perspective. Pharmacoeconomics. 25(4), 329-342 (2007).

McLeod C, Fleeman N, Kirkham J, et al. Deferasirox for the treatment of iron overload associated with regular blood transfusions (transfusional haemosiderosis) in patients suffering with chronic anaemia: a systematic review and economic evaluation. Health Technol. Assess. 13(1), 1-121 (2009). 